\title{
The Role Stress Has on the Creative Process of Problem-Solving Projects: A Case Study of Individuals and Collaboration
}

\author{
Lilia Gomez-Lanier ${ }^{1}$ \\ ${ }^{1}$ Assistant Professor, Department of Textiles, Merchandising and Interiors, University of Georgia, United States \\ Correspondence: Lilia Gomez-Lanier, Assistant Professor, Department of Textiles, Merchandising and Interiors, \\ University of Georgia, United States.
}

Received: March 16, 2018

doi:10.11114/ijsss.v6i5.3234
Accepted: April 8, $2018 \quad$ Available online: April 23, 2018

URL: https://doi.org/10.11114/ijsss.v6i5.3234

\begin{abstract}
This study examined interior design and fashion merchandising students because they creatively solve everyday consumer problems and employers competitively screen graduates for their creative and collaborative abilities. Students in these fields not only have to fulfill course requirements, but they also must exhibit a high level of creativity and be able to work with others. To examine the influence stress may have on the creative process of problem-solving, students working alone were compared to students working in teams. From this central focus, the study explored three research questions (RQ). RQ1 asked if stress is more likely to occur when students work alone as opposed to working in teams. RQ 2 pertained to what parts of the design process are stressful when working on a team as well as what parts are stressful when working alone. RQ3 dealt with how students deal with stress when working alone, and how do they deal with it when working on a team. The research study employed a mixed methods approach involving an online 29 questions survey developed by the researcher that asked students to rank their perceptions using a five-point Likert scale. At the end of the online survey students answered one open-ended question that captured students' perceptions of stress. The outcomes indicated that individuals working alone and in teams had specific stress indicators at different points throughout the problem-solving assignments. Additionally, the study showed the value of social connectivity and freedom to select team members.
\end{abstract}

Keywords: stress, collaboration, problem-solving, creativity, design

\section{Introduction}

\subsection{Introduce the Problem}

When students are obtaining a professional degree, there is a universal occurrence on today's higher education campuses; these demands are felt by students throughout their educational pursuits and result in an increased level of stress (Hamaideh, 2009; Bataineh, 2013). Today's job market requires applied art students to exhibit a high level of creative capital and be able to work with others on problem-solving projects to fulfill their goals. Today's marketplace is increasingly interdependent upon individuals with the ability to multitask and work with others (Kichuk \& Wiesner, 1997). So much so that researchers suggest that, the future success of businesses relies on their ability to harness the creative capital of their employees (Florida \& Goodnight, 2005; Rego, Sousa, Pina e Cunha, Correia, \& Saur-Amaral, 2007).

Although given the structure of collaborative projects, the potential level and nature of stress brought about by the creativity of design challenges vary within the context of a student-team project or an individual designer. This study explored the role stress has on the creative process of interior design and fashion merchandising students when problem-solving working alone or in a team. The two applied arts fields were selected because they routinely develop creative solutions as individual designers and in collaborative team projects. While creativity in these two fields has primarily been perceived as being individually produced, the reality is that the workplace demands out-of-the-box thinking and new ways of creative problem-solving in a collaborative environment (Cross \& Cross, 1995).

\subsection{Importance of the Problem}

Collaboration plays a vital role in interior design and fashion merchandising because through the collaborative process diversity of ideas flourishes and is nurtured to create a product that enhances the daily life of others. Collaborative 
teamwork, as suggested by Winer and Ray (1994), is the process that brings together individuals to create and develop new ideas and ways to solve problems. Furthermore, Chen (2007) suggests that collaborative teams are formed with individuals whose talent, energy, and skills are integrated into a team, and this collective capacity to innovate becomes greater than the sum of individual contributions.

A study of stress and its impacts on the design creativity process of collaborative teams versus individuals offers a unique opportunity to explore how students perceive stress and the creative process. In collaborative projects, one might think it is easier to generate numerous ideas; however, it is equally as difficult to bring about a consensus on a single idea. Although one might think it would be easier to accomplish work with the support of teammates, it is equally as difficult to manage the work of teammates for one end goal.

\subsection{Relevant Scholarship}

\subsubsection{Stress}

Research conducted by Bataineh (2013) states that university students face an increased risk of experiencing stress as they proceed through their academic endeavors. Higher education students are particularly vulnerable to stress because they are in a transition phase in their lives, which is dependent young adult to independent adult. Causes of stress may include academic course requirements, time management, financial independence and difficulty adjusting to new social relationships (Pandya, Deshpande, \& Karani, 2012). Research further indicates that student success is influenced by students' emotions, academic expectations, and academic performance (Abouserie, 1994). Students that exhibit high levels of stress are more likely to become depressed and withdraw from their course and/or higher education institution (Dixon \& Robinson-Kurpius, 2008).

Researchers Bonn and Bonn (2000) postulate that stress pertains to a perceived imbalance between demands and an individual's ability to obtain the resources to meet those demands. The literature further suggests that stress is an ever-evolving complex phenomenon due to an individual's self-evaluation of abilities, available personal resources, surrounding environment, and emotions, such as insecurity, feelings of being overwhelmed, and self-worth (Dixon \& Robinson-Kurpius, 2008; Parker, Paterson, \& Hadzi-Pavlovic, 2015; Smith \& Lilly, 2016). Consequently, bringing awareness to that stress is not only psychological but also relates to the physical, social, and mental states of an individual.

Literature suggests that stress can be both positive and negative, depending on the quantity (Monat \& Lazarus, 1977; Pandya et al., 2012; Alawad \& Slamah, 2014). Positive stress, known as eustress, is the amount of stress needed for an active and healthy life. However, distress, the negative stress, leads to strained physical or emotional development that ultimately can lead to physical and emotional illnesses, such as sleep deprivation and loss of self-worth. Both, positive and negative stress are a result of predictable or unpredictable causes depending on the individual's ability to control demands, such as life events, personal relationships, and work-related occurrences (Lazarus \& Folkman, 1984; Alawad \& Slamah, 2014).

\subsubsection{Creativity and Stress}

Research conducted by Bataineh (2013) suggests that fear of failure is a major source of stress among undergraduate students. This finding is particularly important for students in the creative fields such as interior design and fashion because students typically work in open studios where the instructor openly gives feedback on work to students and students closely interact with one another. In such an open learning environment where students present their work to peers, instructors, and guests, students have been found to feel vulnerable. According to research studies conducted by Dixon and Robinson-Kurpius (2008) and Blair (2007), students in creative endeavors have difficulties disengaging themselves from their work because their work is a symbol of the student's ability to be innovative within a context of creative individuals. The student's work is the student's creative persona. Furthermore, positive or negative feedback will influence a student's self-worth, particularly in the case of negative feedback, which can lead to depression and stress.

Although one assumes that working as a team, the team as a whole offers greater opportunities for solving complex problems. Managing collaboration can be challenging. In today's global, interconnected community, creativity is a collective phenomenon that supports individual and group achievements. In particular, group efforts that maximize the exploration of ideas and viewpoints to problem-solve an issue. Creativity is a coordinated effort shaped by individual and group life experiences (Stahl, 2006). Within the context of collaborative environments, it is essential to maintain open and frequent communication among teammates to discourage issues arising from miscommunication that ultimately lead to stress. Group members must be able to freely express problem-solving concepts and build on personal experiences to resolve present-day problems. According to Smith and Lilly (2016), miscommunication within a collaborative environment can trigger stress that may alter a student's learning potential and problem-solving abilities. 
Research has shown that there are differences in group performances and that success relates to teammates' higher acceptance of proposals, correct evaluation of ideas, and politeness increased the chances academic success (Barron, 2003; Chiu, 2008). Teams require more trust because of the high degree of interdependency needed for teammates to complete their tasks.

Collaborative efforts have been shown to foster creative analysis and design while increasing classroom overall performance. According to the literature, an individual's problem-solving abilities can lead to effective coping mechanisms and adaptive behavior because creative problem-solving often involves a conglomeration of mental processes that are in constant flux such as concentration, ideation, sorting, verification, and integration (Witmer, 1985; Carson \& Runco, 1999). Further research indicates what types of motivation seem to correlate with creativity and stress. Extrinsic motivation, which is motivation to perform to obtain a reward, has been shown to negatively influence creativity; while intrinsic motivation, which is an individual's internal drive to succeed, is fundamentally positive influence on creativity. For instance, research has shown that deadlines tend to reduce intrinsic interests in tasks, and extrinsic motivators diminish the quality of work (Eisenberger \& Cameron, 1996; Amabile, 1985; Ceci \& Kumar, 2016)

\subsection{Hypothesis and Correspondence to Research Design}

The study sought to examine the role stress has on the creative process of problem-solving assignments when students work alone when compared to students working in teams. From this central focus, the study explored three research questions:

RQ1: Is stress more likely to occur when students work alone as opposed to when students work in teams?

RQ2: (a) What parts of the design process are stressful when working on a team, and (b) what parts are stressful when working alone? Does this stress level change after working on a team project?

RQ3: How do students deal with stress when (a) working alone, and (b) working on a team?

\section{Method}

This mixed methods study has both theoretical and practical significance. By gaining a clearer understanding of the influences stress may have on the creative process, this study contributes toward a discussion on reducing stress while simultaneously encourage creative problem-solving rather than discourage it.

\subsection{Participants}

The study took place at a large public institution of higher education in the southeast area of the United States. Participants were drawn from two interior design courses and two fashion merchandise courses. Although the participants came from four different courses and student projects varied in scope and context, the participants shared one detail - they all participated in individual and team projects over the course of the academic semester. Of the 33 fashion merchandising students, there were 29 seniors, three juniors, and two sophomores. The 20 interior design students were composed of two seniors, nine juniors, and eight sophomores. Of the total 53 students that volunteered to be participants, the student summary is 31 seniors, 12 juniors, and 10 sophomores. All participants were females. For data analysis, all participants in the two fashion courses are referred to as Fashion in the analysis tables, while all the participants in the two interiors courses are referred to as Interiors in the analysis tables.

\subsection{Procedures}

After the study obtained IRB approval, students were introduced to the purpose of the study and invited to participate. Although there were a few male students in the fashion merchandising class, only the female students asked for consent forms, while the interior design courses were composed entirely of female students. Once students volunteered to be a part of the study and signed a consent form, students were asked to complete the same online survey at the beginning and end of their individual and team projects. The researcher shared links to the online pre- and post-tour surveys with students via email and consent form.

The researcher used the online service Survey Monkey ${ }^{\circledR}$ to allow students to conveniently complete the surveys and allow the researcher to have the data efficiently collected and formatted in the Statistical Package for the Social Sciences version 22 (SPSS 22). At the end of the academic semester, data were downloaded. Using SPSS 22 descriptive statistics, Friedman's test and Wilcoxon Signed Rank tests were used to analyze the survey responses related to the significant differences in stress between individual and group projects, while the qualitative data were reviewed and distilled for common themes.

\section{Tools of the Study}

\subsection{Instrument}

The online survey, developed by the researcher, consisted of both quantitative and qualitative parts. The quantitative 
part dealt with 28 closed-ended questions that uncovered general demographic information and ranked students' perceptions measured with a 5-point Likert-type scale ranging from (1) strongly agree to (5) strongly disagree. In the meantime, the qualitative part asked an open-ended question that captured students' perceptions of stress at the end of the online survey. By administering the same survey before and after the individual and group projects, the researcher could explore students' attitudes and perceptions toward stress while working alone and in groups. Questions one-two sought general information on students' academic levels and academic majors. The rest of the quantitative section was divided into three research questions (RQ) concerning stress. RQ1 is addressed with questions three thru 10, which ask whether stress is more likely to occur with students working alone as opposed to working in teams. Questions 11-18, which focus on RQ2, pertained to what parts of the design process are stressful when working on a team as well as what parts are stressful when working alone. RQ3 is addressed by questions 19-28, which asked how students cope with stress when working alone and how they cope with it when working on a team.

The qualitative phase consisted of question number 29, which provided information on the participants' abilities to cope with stress when working alone and when working on a team. Question 29 also asks if participants' opinions changed after they worked on a team project. The researcher transcribed the data, noted, and coded by hand similar phrases and content. The researcher wrote a case study for each participant, and then performed a cross-case, comparative analysis of the data collected, following the procedure recommended by Patton (2002) for qualitative analysis. Next, the data were broken into topics, and similar statements coded, leading to the identification of themes. The researcher found regularities within the data that validated the accuracy of the themes and represented the most prominent components of themes, which affected participants' experiences.

\subsection{Design Projects}

The students' course assignments, distribution of design tasks, and responsibilities for both the interior design and fashion merchandising courses were based on real-world problems in scope and content. In creative fields like interior design and fashion merchandising, it is commonplace for individuals to work on design problems alone and in groups at certain times. Thus, students in the examined courses when working alone or in groups were exposed to open studio critiques, deadlines, in-class presentations to peers and guests, and progress reports.

\section{Findings and Discussion}

\subsection{Quantitative Analysis}

\subsubsection{Research Question 1 (RQ1)}

Is stress more likely to occur when students work alone as opposed to when students work in teams?

HO1: There are no significant differences in stress occurring with students working alone as opposed to working in teams.

HA1: There are significant differences in stress occurring with students working alone as opposed to working in teams.

With survey questions one and two pertaining to demographic information, survey questions three through 10 were used in the quantitative analysis seeking to answer RQ1. The researcher performed a reliability test to determine whether survey questions three through 10 measured the same construct. The researcher found a Cronbach's alpha of 0.782 for the pre-project tour survey responses and 0.783 for the post-project tour survey responses, indicating that the construct is reliable in both surveys.

Descriptive statistical analyses were run to find the mean scores for the responses to both surveys. The means for pre-project questions 5 and 9 suggest that participants were neutral on working on teams regardless of size and criticism. Additionally, students were the least stressed on working with friends. Participants' answers suggested that students perceived the most stress when they have to work with deadlines, being on teams, and trusting peers.

When comparing both surveys, the means for questions three to 10 were lower for the post-project than the pre-project, indicating that participants at the end of the semester were more likely to be overall more stressed about working on teams (regardless of size), trust, deadlines, conflicts, and criticism. Although, it is interesting to note that participants at the end and beginning of the semester felt that working on teams with friends was the least stressful (see Table 1). 
Table 1. RQ1 Mean Responses to Research Survey Question 1

\begin{tabular}{|c|c|c|c|c|}
\hline \multirow[t]{2}{*}{ Survey Questions } & Pre-project & Pre-project & Post-project & Post-project \\
\hline & Mean & $\mathrm{SD}$ & Mean & $\mathrm{SD}$ \\
\hline $\begin{array}{l}\text { (3) I am more stressed working in student teams as opposed to } \\
\text { alone. }\end{array}$ & 2.6604 & 1.09093 & 2.4340 & .97091 \\
\hline $\begin{array}{l}\text { (4) I am more stressed working in teams as opposed to } \\
\text { working alone because I have to be able to trust my } \\
\text { teammates to be as creative as I am in solving problems. }\end{array}$ & 2.6981 & .93201 & 2.4906 & .95319 \\
\hline $\begin{array}{l}\text { (5) I am more stressed when working in teams regardless of } \\
\text { team size. }\end{array}$ & 3.0000 & 1.00000 & 2.8113 & 1.09292 \\
\hline $\begin{array}{l}\text { (6) I am more stressed working in teams when teammates are } \\
\text { assigned. }\end{array}$ & 2.7547 & 1.09027 & 2.5472 & 1.15302 \\
\hline $\begin{array}{l}\text { (7) I am more stressed working in teams when teammates are } \\
\text { friends. }\end{array}$ & 3.6415 & 1.00181 & 3.2642 & 1.05886 \\
\hline $\begin{array}{l}\text { (8) I am more stressed working in teams because of the } \\
\text { likelihood of conflicts. }\end{array}$ & 2.8868 & 1.04992 & 2.5283 & .95281 \\
\hline $\begin{array}{l}\text { (9) Having my solutions critiqued by teammates is more } \\
\text { stressful when compared to working alone. }\end{array}$ & 3.0566 & 1.11657 & 2.9623 & .97984 \\
\hline $\begin{array}{l}\text { (10) Having to be responsible for meeting deadlines is more } \\
\text { stressful for me when working in teams when compared to } \\
\text { working alone. }\end{array}$ & 2.6792 & 1.28263 & 2.2642 & 1.02189 \\
\hline
\end{tabular}

The researcher also conducted an overall "team stress" rating to explore further whether students had become more stressed by the end of the semester. The pre-project overall team stress means of 23.4100 was higher than the post-project overall team stress mean of 21.3018, thus suggesting and reinforcing the descriptive analysis shown in Table 1. Students after working on projects experienced less stress in teams.

A Wilcoxon Signed Rank test was completed (Table 2) to examine pre- and post-project preferences toward teamwork with respect to stress. During the pre-project with the exception of questions three, four, and seven, for five out of eight items, there are no significant differences in stress occurring with students working alone as opposed to working in teams for questions three through 10, with $\mathrm{p}>0.05$. However, results show that students are less enthusiastic about teamwork in questions three and four and they seem to prefer working with friends in a team, which is found in the responses from question seven.

In the post-project, with the exception of questions three, four, six, eight, and 10, responses for three out of eight items revealed that there are no significant differences in stress occurring with students working alone as opposed to working in teams, with $\mathrm{p}>0.05$. Findings for question five indicate that, after experiencing teamwork, students remained stressed regardless of team size. For question seven, students grew to become less stressed about working with teammates that are friends. For question nine, students continued to be stressed when critiqued by teammates. Thus, students continued to be stressed when reviewed and working on teams (See Table 2). In other words, from the post-test results the students are still less enthusiastic about teams for questions three and four, but no longer prefer working with friends as shown earlier for question seven and now are less enthusiastic about teams because of conflicts, deadlines and assigned members (questions six, eight and ten). 
Table 2. RQ 1 Wilcoxon Signed Rank Test for Pre-project and Post-project

\begin{tabular}{|c|c|c|c|c|}
\hline \multirow[t]{2}{*}{ Survey Questions } & Pre-project & Pre-project & Post-project & Post-project \\
\hline & $\mathrm{Z}$ value & $\begin{array}{l}\text { Asymp. Sig (2 } \\
\text { tailed) }\end{array}$ & $\mathrm{Z}$ value & $\begin{array}{l}\text { Asymp. Sig. (2 } \\
\text { tailed) }\end{array}$ \\
\hline $\begin{array}{l}\text { (3) I am more stressed working in student teams as } \\
\text { opposed to alone. }\end{array}$ & -2.219 & .026 & -3.710 & .000 \\
\hline $\begin{array}{l}\text { (4) I am more stressed working in teams as opposed to } \\
\text { working alone because I have to be able to trust my } \\
\text { teammates to be as creative as I am in solving problems. }\end{array}$ & -2.270 & .023 & -3.467 & .001 \\
\hline $\begin{array}{l}\text { (5) I am more stressed when working in teams regardless } \\
\text { of team size. }\end{array}$ & -.044 & .965 & -1.304 & .192 \\
\hline $\begin{array}{l}\text { (6) I am more stressed working in teams when teammates } \\
\text { are assigned. }\end{array}$ & -1.714 & .087 & -2.703 & .007 \\
\hline $\begin{array}{l}\text { (7) I am more stressed working in teams when teammates } \\
\text { are friends. }\end{array}$ & 3.912 & .000 & 1.689 & .091 \\
\hline $\begin{array}{l}\text { (8) I am more stressed working in teams because of the } \\
\text { likelihood of conflicts. }\end{array}$ & -.922 & .357 & 3.286 & .001 \\
\hline $\begin{array}{l}\text { (9) Having my solutions critiqued by teammates is more } \\
\text { stressful when compared to working alone. }\end{array}$ & .594 & .552 & -.288 & .773 \\
\hline $\begin{array}{l}\text { (10) Having to be responsible for meeting deadlines is } \\
\text { more stressful for me when working in teams when } \\
\text { compared to working alone. }\end{array}$ & -1.871 & .061 & -4.299 & .000 \\
\hline
\end{tabular}

4.1.2 Research Question 2(RQ2)

(a) What parts of the design process are stressful when working on a team, and (b) what parts are stressful when working alone? Does this stress level change after working on a team project?

HO2: There are no significant differences in what parts of the design process are stressful when working on a team, and no significant differences when working alone.

HA2: There are significant differences in what parts of the design process are stressful when working on a team, and/or significant differences when working alone.

A reliability test was not performed because these questions are not measuring an overall construct; instead, the answers to these questions will be compared and contrasted to one another. Descriptive statistics were performed to calculate the mean score for responses to both surveys to explore what parts of the design process are stressful when working on a team (see Table 3). The mean for the pre-project survey leaned neutral toward negative responses at the beginning of the semester. However, by the end of the semester, the means moved from neutral toward negative, with the exception of question 13, which overwhelmingly leaned toward agreeing that students are more stressed when deciding on final solutions while on a team.

In summary, the findings indicated that at the beginning of the semester, participants perceived the least amount of stress when deciding on a final solution and the most stress when asked to conduct research. However, by the end of the semester, students working on teams had become less stressed about presenting to the class and the most stressed when deciding on a team's final solution (see Table 3).

Table 3. RQ2 Pre- and Post-Project Mean Responses to What Parts are Stressful When Students Work in Teams

\begin{tabular}{lcccc}
\hline Survey Questions & Pre-project & Pre-project & Post-project & Post-project \\
\cline { 2 - 5 } & Mean & SD & Mean & SD \\
\hline $\begin{array}{l}\text { (11) As a team member, I am more likely to be stressed } \\
\text { when researching a solution. }\end{array}$ & 3.2264 & .86916 & 3.0566 & .92850 \\
$\begin{array}{l}\text { (12) As a team member, I am more likely to be stressed } \\
\text { when I begin to develop solutions. }\end{array}$ & 3.4340 & .82063 & 3.2453 & .82987 \\
$\begin{array}{l}\text { (13) As a team member, I am more likely to be stressed } \\
\text { when I have decided on a final solution. }\end{array}$ & 3.6038 & .79275 & 1.3585 & .48415 \\
$\begin{array}{l}\text { (14) As a team member, I am more likely to be stressed } \\
\text { when I present my solution to the class. }\end{array}$ & 3.4717 & .93240 & 3.3585 & 1.02083
\end{tabular}

Regarding what parts of the design process are stressful when working alone, the pre-project findings suggested that participants perceived themselves as being less stressed when researching, developing solutions, and deciding on a final solution (see Table 4). Nevertheless, presenting a solution to the class brought the most stress to students. By the end of the semester, the post-project findings indicated that students' working alone became slightly more stressed about doing research and deciding on final solutions. In the meantime, students working alone grew slightly less stressed on developing solutions and extremely less stressed about presenting to the class. 
Table 4. RQ 2 Pre- and Post-Project Mean Responses to What Parts are Stressful When Students Work in Alone

\begin{tabular}{|c|c|c|c|c|}
\hline \multirow[t]{2}{*}{ Survey Questions } & Pre-project & Pre-project & Post-project & Post-project \\
\hline & Mean & SD & Mean & SD \\
\hline $\begin{array}{l}\text { (15) I am more likely to be stressed when researching a } \\
\text { solution. }\end{array}$ & 3.2642 & .88036 & 3.1887 & .94170 \\
\hline $\begin{array}{l}\text { (16) I am more likely to be stressed when I begin to } \\
\text { develop solutions. }\end{array}$ & 3.3019 & .91115 & 3.4717 & .84589 \\
\hline $\begin{array}{l}\text { (17) I am more likely to be stressed when I have } \\
\text { decided on a final solution. }\end{array}$ & 3.4717 & 1.06706 & 3.4151 & 90796 \\
\hline $\begin{array}{l}\text { (18) I am more likely to be stressed when I present my } \\
\text { solution to the class. }\end{array}$ & 2.3208 & 1.08793 & 2.6792 & 1.08793 \\
\hline
\end{tabular}

Pre-project. A Friedman test was used to better understand the different stress levels that occurred in the design process when students worked in teams or alone throughout the semester. A Friedman test was completed for comparing participants working on teams at the beginning of the semester, which is reflected in the responses to questions 11,12 , 13 , and 14. The findings resulted in a $\chi^{2}(3)=6.747$ with a $p$-value of .080 . These results suggested that there are no statistically significant differences with stress across these different design phases at the 0.05 level of significance. Therefore, the null hypothesis is not rejected.

In comparison, the Friedman test for pre-project students working alone findings resulted in $\chi^{2}(3)=48.026, p<0.001$, which suggested that there are statistical differences with stress across the design phases, thus, causing the null hypothesis to be rejected. Post-hoc pairwise comparisons suggested that students working alone are most stressed when presenting their final solutions to the class, which supports the descriptive analysis.

Post-project. The Freidman test for students working on teams resulted in $\chi^{2}(3)=11.397, p<0.010$, and showed that there are statistically significant differences with stress across design phases. Therefore, the null hypothesis is rejected. Note that although the analysis showed significant differences in stress across the design phases when stress was compared with one design phase to another using post-hoc pairwise comparison, no significant differences across phases were found after adjusting for multiple comparisons.

In comparison, the Friedman test for students working alone indicated a chi-square or $\chi^{2}(3)=20.398, p<0.001$, which indicated that there were statistical differences in stress across the design phases. Even though students working alone experienced various activities throughout the semester, post-hoc pairwise comparisons indicated that students continued to be the most stressed in the presentation design phase. These findings not only support the descriptive analysis, but they also suggested that regardless of activities, students working alone were the most stressed when presenting their final solution to the class.

\subsubsection{Research Question 3 (RQ3)}

How do students deal with stress when (a) working alone, and (b) working on a team?

HO3: There are no significant differences in how students deal with stress when working alone and how they deal with it when working on a team.

HA3: There are significant differences in how students deal with stress when working alone and how they deal with it when working on a team.

A reliability test was not performed because these questions are not measuring an overall construct; instead, the answers to these questions will be compared and contrasted to one another. Descriptive statistics were completed to calculate the combined mean score for the responses to questions 19 through 23 for both the pre- and post-project surveys (see Table 5) for how students deal with stress when working on teams. The mean for the pre-project survey questions 19 through 23 suggested that participants working on teams had a positive to neutral perception for talking to the instructor and their peers, taking time to reflect, and conducting additional research when developing solutions. However, responses for question 23 suggested that students see it as a negative to be stressed about developing a solution and starting over when on a team. The post-project responses suggested that students grew slightly more negative about talking to the instructor and teammates and taking time for reflection. 
Table 5. RQ 3 Mean Responses to Students Working on Teams

\begin{tabular}{|c|c|c|c|c|}
\hline \multirow[t]{2}{*}{ Survey Questions } & Pre-project & Pre-project & Post-project & Post-project \\
\hline & Mean & SD & Mean & $\mathrm{SD}$ \\
\hline $\begin{array}{l}\text { (19) When working on a team and stressed about } \\
\text { developing solutions to the assignment, I talk to the } \\
\text { instructor. }\end{array}$ & 2.3396 & .85358 & 2.4906 & .91194 \\
\hline $\begin{array}{l}\text { (20) When working with a team and stressed about } \\
\text { developing solutions to the assignment, I stop working } \\
\text { on the assignment for a period of reflection. }\end{array}$ & 2.7736 & 1.01226 & 2.8868 & 1.01262 \\
\hline $\begin{array}{l}\text { (21) When working with a team and stressed about } \\
\text { developing solutions to the assignment, I talk to my } \\
\text { teammates. }\end{array}$ & 1.9623 & .75860 & 2.1132 & .72484 \\
\hline $\begin{array}{l}\text { (22) When working with a team and stressed about } \\
\text { developing solutions to the assignment, I conduct } \\
\text { additional research on the topic. }\end{array}$ & 2.5283 & .93240 & 2.3962 & .81664 \\
\hline $\begin{array}{l}\text { (23) When working with a team and stressed about } \\
\text { developing solutions to the assignment, I start over. }\end{array}$ & 3.6226 & .81397 & 3.4906 & .97315 \\
\hline
\end{tabular}

Descriptive statistics were performed to calculate the combined mean scores for responses to questions 24 through 28 for both pre- and post-project surveys (see Table 6) for how students deal with stress when working alone. The mean for the pre-project survey questions $24,25,26$, and 28 suggested that participants working alone had a positive perception for talking to the instructor and their peers, taking time for reflection, and starting over when stressed. However, post-project students indicated that they were slightly more negative about talking to the instructor and their peers as well as taking a break for reflection. Moreover, students working alone became much less willing to start over; however, they became more willing to conduct additional research to deal with stress when working alone.

Table 6. RQ 3 Mean Responses to Students Working Alone

\begin{tabular}{|c|c|c|c|c|}
\hline \multirow[t]{2}{*}{ Survey Questions } & Pre-project & Pre-project & Post-project & Post-project \\
\hline & Mean & SD & Mean & $\mathrm{SD}$ \\
\hline $\begin{array}{l}\text { (24) When working alone and stressed about } \\
\text { developing solutions to the assignment, I talk to the } \\
\text { instructor. }\end{array}$ & 2.3019 & .86791 & 2.5094 & .97315 \\
\hline $\begin{array}{l}\text { When working alone and stressed about } \\
\text { developing solutions to the assignment, I stop working } \\
\text { on the assignment for a period of reflection. }\end{array}$ & 2.3774 & .92459 & 2.5849 & .92889 \\
\hline $\begin{array}{l}\text { (26) When working alone and stressed about developing } \\
\text { solutions to the assignment, I talk to my classmates. }\end{array}$ & 2.3585 & .85697 & 2.5094 & 1.01190 \\
\hline $\begin{array}{l}\text { (27) When working alone and stressed about } \\
\text { developing solutions to the assignment, I conduct } \\
\text { additional research on the topic. }\end{array}$ & 3.5283 & .91155 & 2.4151 & .77046 \\
\hline $\begin{array}{l}\text { (28) When working alone and stressed about } \\
\text { developing solutions to the assignment, I start over. }\end{array}$ & 2.3396 & .85358 & 3.2830 & .86330 \\
\hline
\end{tabular}

Pre-project. A Friedman test was used to understand better the different ways students working in teams or alone deal with stress across the semester. The Friedman test compared responses for questions 19 through 23 to measure how students working on teams deal with stress. The analysis showed an outcome of a chi-square of 74.675 or $\chi^{2}(4)=$ 74.675 and a p-value of $<0.001$, which indicated that there are statistically significant differences in the way stress is dealt among students working on teams. Post-hoc pairwise comparisons indicated that the only difference occurred between students working on teams seeking help from peers (question 21, most likely) and deciding to stop working to search for other solutions (question 23, least likely).

When students work alone, Freidman's test findings for questions 24 through 28 suggested that there were statistically significant differences with how students deal with stress. The findings for working alone showed a chi-square of 58.620 or $\chi^{2}(4)=58.620$ and a p-value of $\mathrm{p}<0.001$; thus, the null hypothesis is rejected. Post-hoc pairwise comparisons showed that students are less likely to respond, as in question 28 , than in any other way that is choosing to start over in search of another solution.

Post-project. The Freidman test of questions 19 through 23 for students working on teams showed a chi-square or $\chi^{2}$ (4) $=62.433$, a p-value of 0.010 , which indicated that there are statistically significant differences with how students on teams deal with stress. Therefore, the null hypothesis is rejected. Post-hoc pairwise comparisons indicated that students were significantly less likely to report starting over than all other options (with the exception of stopping to work for a period of reflection); students were less likely to stop working for a period of reflection than to talk to their teammates.

Regarding students working alone, the Friedman test for questions 24 through 28 suggested that there were statistically significant differences with how students deal with stress, which was a similar finding for students working on teams. 
The findings indicated a chi-square or $\chi^{2}(4)=25.249, \mathrm{p}<0.001$; thus, the null hypothesis is rejected. Post-hoc pairwise comparisons indicated that students were less likely to stop working in search of other solutions when they were stressed. This last finding indicated that regardless of student experiences, they remained less likely to stop working in search of other solutions as a response to stress when working alone.

\subsection{Qualitative Analysis}

Whereas the quantitative analysis indicated an overall participant perception of stress when working alone or in teams, survey question 29 provided a clearer, qualitative understanding of the overall stress mechanisms and experiences of the participants. Question 29 asked participants to comment on how they might cope with stress when working alone or on a team. Of the 53 participants, 23 pre-project participants and 12 post-project participants responded to question 29 . However, the responses revealed themes and subthemes that provided an additional view into how students deal with stress after working on teams. The pre- and post-project themes are shown in order of frequency, with number one being the most frequently mentioned (see Table 11).

Table 11. Qualitative Themes

\begin{tabular}{|c|c|c|c|}
\hline \multicolumn{4}{|c|}{ Themes } \\
\hline Pre-project Themes & Subthemes & Post-project Themes & Subthemes \\
\hline (1) Time management & $\begin{array}{l}\text { Proactive, mini-deadlines, } \\
\text { charts, plan ahead, workload }\end{array}$ & (1) Project management & $\begin{array}{l}\text { Size of group, incomplete } \\
\text { work }\end{array}$ \\
\hline (2) Distractions & $\begin{array}{l}\text { Take breaks, step back, } \\
\text { exercise, food, social media, } \\
\text { music, } \\
\text { brainstorming }\end{array}$ & (2) Work ethics & Trust, correctness of work \\
\hline (3) Support system & Family, peers, friends & (3) Distractions & $\begin{array}{l}\text { Naps, clean house, music, } \\
\text { sports }\end{array}$ \\
\hline (4) Motivation & $\begin{array}{l}\text { Grades, scholarships, innate } \\
\text { desire to succeed }\end{array}$ & (4) Time management & Lists, charts \\
\hline
\end{tabular}

The analysis indicated four pre-projects and four post-project stress themes that were coping mechanisms. Of the various themes, the findings suggested that participants perceived time management and distractions as two valuable coping mechanisms throughout the semester, regardless of whether they worked with others or alone. Although time management and distractions were the two most used pre-project coping mechanisms, that was no longer the case at the end of the semester. At the beginning of the semester, participants perceived support system and motivation as coping mechanisms. However, by the end of the semester, work ethics and project management had replaced the two aforementioned themes.

The following quotations offer a pre-project representative sample of participants' statements:

Time management theme - Participant stated, "I make a plan with deadlines so I have certain parts of what I'm working on done and I do not procrastinate."

Time management theme - Participant indicated, "Creating a timeline for the project and game plan helps with group work and working alone.

Distraction theme - Participant stated, "I rarely get stressed. However, when adversities try to come my way, I just take a break, relax, and pray. Then when I get my mind right I begin to seek problem-solving solutions such as consulting others or furthering my research."

Distraction theme - Participant stated, "I find that the best way for me to deal with stress when working alone or with a group is to take a step back from the problem for a while and clear my head."

Support system theme - Participant indicated the following: "I talk to my mom because she has great advice and take a minute to reflect and think twice."

Support system theme - Participant stated, "I ask someone for help or talk to someone! Figuring or solving things alone can cause stress."

Motivation theme - Participant suggested the following: "In any student related situation of stress, there is usually a 'freak-out, I just want to give up' moment and then a realization that this (whatever it is) is for a grade. That grade is usually what pushes us forward for fear of failing which leads to a loss of HOPE scholarship. Therefore, in that, I think the coping is more fear of failure and usually after the initial 'freak-out' moment, we are able to complete the assignment given. The people we 'vent' to about these assignments are usually friends not on the project or family ( $\mathrm{mom} / \mathrm{dad}) . "$

The following statements offer a representative sample of participants' comments related to their experiences post-projects: 
Project management theme Participant stated the following: "I do not cope with stress well, especially in group settings. Sometimes group projects can be more stressful especially if other members don't do their parts."

Work ethics theme - Participant indicated the following statement: "It's hard when working with a team because your work ethic is not yours and that makes it hard to trust them and how they get work done."

Work ethics theme - Participant stated, "It is very stressful sometimes working in a team because I like to get my work done right away and am very precise and want to make sure everything is correct. In teams it makes it harder to do this, and with our busy schedules is hard to meet up to work on projects."

Distraction theme - Participant stated, "I tend to take breaks to refresh my mind when tired and stressed. Team or not."

Distraction theme - Participant stated, "I exercise, take a nap, clean and organize my room or house, listen to music, play sports and craft."

Time management theme - Participant indicated, "The biggest stress factor for group assignments with me is lining up everyone's schedule to meet at least once. I make many lists whether alone or with a team. It calms me down to see all that I have to do."

Time management theme - Participant provided the following statement: "I'm usually more stressed with working on a team due more to time management. When I work alone, I can manage my own time instead of having to manage my time around others."

The post-project findings suggested that team projects brought stress to teammates because student grades and class statuses were dependent upon all teammates doing their work in a timely manner according to what teammates agreed upon. The lack of control of teammates' actions and not knowing that individuals would put their best effort forward to fulfill team tasks was stressful, which in turn further influenced team communication, planning and dependability.

\subsection{Limitations}

Although every effort was taken to make this a comprehensive study on stress and its influence on students, the author recognizes that the study has a few limitations. The first limitation pertains to only having two disciplines represented in this study, because students working in teams is a common practice found throughout higher education, regardless of field of study. The second limitation pertains to the study's sample size being limited to less than 100 participants, thus the study's findings cannot be generalized to a larger population. Lastly, the study's participants were limited to undergraduate students, which means that graduate students, higher education's second student population, did not play a role in the study.

\section{Conclusion, Implications and Recommendations}

The findings suggest that after experiencing team projects, students were more likely to be stressed about working on teams, although working on teams with friends was found to be less stressful. This finding supports the research Bonn and Bonn (2000) conducted on the perceived imbalance between demands and an individual's ability to obtain the resources to meet those demands. Although working with friends may be comforting because students understand their idiosyncrasies and abilities of friends, the fact remains that regardless of who is on the team, deadlines are required to be met, which requires teammates to trust that their peers will complete the work. Consequently, the intangible resource of trust in the abilities of others and dependency on others to fulfill responsibilities agreed to as a team member are key to a team's success.

The study found that for students working in teams there were major differences in stress. Students adapted from not being overwhelmed with stress at any particular phase to being very stressed about deciding on a final team solution and the least stressed when presenting to the class. This finding adds credence to the positive and negative stress research Lazarus \& Folkman (1984) and Alawad \& Slamah (2014) conducted. The positive stress in this study refers to the adaptability of students and the reduction of stress when relying on teammates that have stronger communication skills when presenting to the class team solutions, while negative stress refers to the unpredictable demands of deciding on a final team solution. Deciding on a final team solution required students to have the necessary and comparable skills and knowledge to complete the assignment at the necessary level to achieve high marks. A student's effort within a team may not be equal amongst teammates nor reflected accurately in the final grade.

Although, students listed time management tools, strong work ethics, and the avoidance of procrastination as mechanisms to cope with stress at the beginning and end of projects, the selection process of teammates was also a stress coping mechanism that this study has shown to be relevant. Even though students cannot fully control the attitudes, motivation, and behavior teammates have toward completing the work, students will be more apt to be comfortable providing opinions to teammates that are friends. As Stahl (2006) and Smith \& Lilly (2016) in their research indicate open and 
constant communication amongst teammates as central to the team's success regardless of whether students are friends or not. Due to the possibility of not having ample time or ability to complete agreed to team responsibilities, through open communication students will be less likely to be stressed and more motivated to work and explore new solutions.

When students worked alone, the study found that during the design process participants perceived themselves less stressed when researching, developing solutions, and deciding on a solution; while, more stressed about presenting to the class. Presenting in front of peers and the instructor as being the most stressful phase may result from students seeing their creative work as a representation of themselves. A student's persona is being challenged with the result affecting a student's confidence in themselves. According to Dixon and Robinson-Kurpius (2008) and Blair (2007) in the creative fields when presenting a project, it is important to be creative in the eyes of others.

Concerning asking peers and instructors for assistance, students on teams were more reluctant to ask for help from peers and instructors. Yet, students working alone were more willing to ask for problem-solving advice from the instructor. This difference between the two groups might stem from students not wanting to appear less creative or unable to problem-solve in front of their peers. As Dixon and Robinson-Kurpius (2008) and Blair (2007) suggest in their research individuals in creative fields, such as those in this study, have difficulty disengaging themselves from their work and may view assistance from others as a weakness. Additionally, a student's inability to control their projects' outcomes and their dependency on others to be creative and complete their work significantly affects the perceived stress levels of students working on teams.

In conclusion, the study revealed that although both sets of students will incur stress at various times throughout the design process, the perceived levels of student stress progressively increased and shifted during the research, exploration, refinement, and finalization design phases of project solutions. Although individual students by their very nature have to be self-reliant on their design abilities, motivation, and communication skills to be successful, perceived stress levels can be managed by students during any design stage, particularly when presenting to peers and instructors, when stress is at the highest. The study further showed that students as individuals bring to the team their unique work ethics and standards, for students working on teams, the study showed that perceived student stress is related to the social interactions of teammates, team organization, and dependency on others. For these three aforementioned factors, the influence trust, comfort, and motivation teammates have with one another to voice their opinions, ideas, and direction of design are all part of team responsibilities and, ultimately, define the success and completion of the design project.

Lastly, this author recommends that future research be undertaken in this area, especially research that includes graduate students and undergraduate students from all academic levels. It is through this recommendation that educators may understand in more holistic terms how stress influences the learning process of all students participating in team projects as well as working alone. Furthermore, it is suggested that future research develop a similar study that explores the research questions as students' progress through their academic levels in an effort to gain insights on stress reducing techniques students may acquire or are no longer used. In addition, since team work is commonly used in various disciplines this author recommends that similar research studies explore the topic using additional fields of studies.

\section{References}

Abouserie, R. (1994). Sources and levels of stress in relation to locus of control and self-esteem in university students. Educational Psychology, 14(3), 323-330. https://doi.org/10.1080/0144341940140306

Alawad, A., \& Slamah, A. (2014). The prevalence of stress among interior design and furniture students. European Scientific Journal, 10(23), 60-73

Amabile, T. M. (1985). Motivation and creativity: Effects of motivational orientation on creative writers. Journal of Personality and Social Psychology, 48(2), 393-399. https://doi.org/10.1037/0022-3514.48.2.393

Barron, B. (2003). When smart groups fail. Journal of the Learning Sciences, 12(3), 307-359. https://doi.org/10.1207/S15327809JLS1203_1

Bataineh, M. (2013). Academic stress among undergraduate student: The case of education faculty at King Saud University. International Interdisciplinary Journal of Education, 2(1), 82-88. https://doi.org/10.12816/0002919

Blair, B. (2007). At the end of a huge crit in the summer, it was crap. I had worked hard but all she said was fine and I was gutted. Art, Design and Communication in Higher Education, 5(2) 83-95. https://doi.org/10.1386/adch.5.2.83_1

Bonn, D., \& Bonn, J. (2000). Work related stress: Can it be a thing of the past? The Lancet Journal, $355(9198), 124$. https://doi.org/10.1016/S0140-6736(05)72040-7

Carson, D., \& Runco, M. (1999). Creative problem solving and problem finding in young adults: Interconnections with stress, hassles, and coping abilities. Journal of Creative Behavior, 33(3), 168-188. https://doi.org/10.1002/j.2162-6057.1999.tb01195.x 
Ceci, M. W., \& Kumar, V. K. (2016). A correlational study of creativity, happiness, motivation, and stress from creative pursuits. Journal of Happiness Studies, 17(2), 609-626. https://doi.org/10.1007/s10902-015-9615-y

Chen, M. H. (2007). Entrepreneurial leadership and new ventures: Creativity in entrepreneurial teams. Creativity and Innovation Management, 16(3), 239-249. https://doi.org/10.1111/j.1467-8691.2007.00439.x

Chiu, M. M. (2008). Flowing toward correct contributions during group problem solving: A statistical discourse analysis. Journal of the Learning Sciences, 17(3), 415-463. https://doi.org/10.1080/10508400802224830

Cross, N., \& Cross, A. C. (1995). Observations of teamwork and social processes in design. Design Studies, 16(2), 143-170. https://doi.org/10.1016/0142-694X(94)00007-Z

Dixon, S., \& Robinson-Kurpius, S. (2008). Depression and college stress among university undergraduates: Do mattering and self-esteem make a difference? Journal of College Student Development, 49(5), 412-424. https://doi.org/10.1353/csd.0.0024

Eisenberger, R., \& Cameron, J. (1996). Detrimental effects of reward: Reality or myth. American Psychologist, 51(11), 1153-1166. https://doi.org/10.1037/0003-066X.51.11.1153

Florida, R., \& Goodnight, J. (2005). Managing for creativity. Harvard Business Review, July-August, 124-131.

Hamaideh, S. H. (2009). Stressors and reactions to stressors among university students. International Journal of Social Psychiatry, 57(1), 69-80. https://doi.org/10.1177/0020764009348442

Kichuk, S. L., \& Wiesner, W. H. (1997). The big five personality factors and team performance: Implications for selecting successful product design teams. Journal of Engineering and Technology Management, 14(3-4), 195-221. https://doi.org/10.1016/S0923-4748(97)00010-6

Lazarus, R. S., \& Folkman, S. (1984). Stress, appraisal, and coping. New York, NY: Springer-Verlag.

Monat, A., \& Lazarus, R. S. (1977). Stress and coping. An anthology. New York, NY: Columbia University Press.

Pandya, B. U., Deshpande, R. C., \& Karani, A. (2012). A study on impact of academic stress on MBA students of Gujarat Technological University. Researcher's World - Journal of Arts, Science and Commerce, 3(3), 20-28.

Parker, G., Paterson, A., \& Hadzi-Pavlovic, D. (2015). Emotional response patterns of depression, grief, sadness and stress to differing life events: A quantitative analysis. Journal of Affective Disorders, 175, 229-232. https://doi.org/10.1016/j.jad.2015.01.015

Patton, M. Q. (2002). Qualitative research and evaluation methods. Thousand Oaks, CA: Sage Publications.

Rego, A., Sousa, F., Pina e Cunha, M., Correia, A., \& Saur-Amaral, I. (2007). Leader self-reported emotional intelligence and perceived employee creativity: An exploratory study. Creativity and Innovation Management, 16(3), 250-264. https://doi.org/10.1111/j.1467-8691.2007.00435.x

Smith, D., \& Lilly, L. (2016). Understanding student perceptions of stress in creativity-based higher education programs: A case study in interior architecture. Journal of Interior Design, 41(2), 39-55. https://doi.org/10.1111/joid.12072

Stahl, G. (2006). Group cognition: Computer support for building collaborative knowledge. Cambridge, MA: MIT Press.

Winer, M., \& Ray, K. (1994). Collaboration handbook: Creating, sustaining and enjoying the journey. St. Paul, MN: Wilder Publishing Center.

\section{Copyrights}

Copyright for this article is retained by the author(s), with first publication rights granted to the journal.

This is an open-access article distributed under the terms and conditions of the Creative Commons Attribution license which permits unrestricted use, distribution, and reproduction in any medium, provided the original work is properly cited. 